\title{
Challenging, co-operating and splitting: a qualitative analysis of how the trade press responded to Cumulative Impact Policies in England and Wales
}

Abbreviated title: Qualitative analysis of English and Welsh trade response to CIPs

\section{Dorothy Hector ${ }^{1}$ \\ Department of Social Policy \\ London School of Economics and Political Science \\ London, United Kingdom}

At the time of writing, Dorothy Hector was a Masters student at the London School of Economics and Political Science. She is currently attending Harvard Law School and her interests include health law.

\section{Elizabeth McGill*}

National Institute for Health, School for Public Health Research

London School of Hygiene \& Tropical Medicine

London, United Kingdom

Elizabeth McGill is a Research Fellow in Systems Evaluation. Her research interests include alcohol policy and systems approaches to public health evaluation.

\section{Daniel Grace ${ }^{2}$}

National Institute for Health, School for Public Health Research

London School of Hygiene \& Tropical Medicine

London, United Kingdom

At the time of writing, Daniel Grace was a Research Fellow at London School of Hygiene \& Tropical Medicine and an Assistant Professor at the University of Toronto. His research interests include social and structural determinants of health, health inequity and critical policy analysis. He is currently an Assistant Professor at the University of Toronto, Dalla Lana School of Public Health, Social and Behavioural Health Sciences.

\section{Matt Egan}

National Institute for Health, School for Public Health Research

London School of Hygiene \& Tropical Medicine

15-17 Tavistock Place, London WC1H 9SH

London, United Kingdom

Matt Egan is an Associate Professor at London School of Hygiene \& Tropical Medicine. His research interests include social and structural determinants of health, health inequalities, healthy environments and alcohol policy.

Word count: 7,857 (including references)

*Corresponding author - Elizabeth McGill

National Institute for Health, School for Public Health Research

London School of Hygiene \& Tropical Medicine

15-17 Tavistock Place, Room 147, London WC1H 9SH

\footnotetext{
${ }^{1}$ Dorothy Hector's current affiliation: Harvard Law School, Massachusetts, USA

2 Daniel Grace's current affiliation: Dalla Lana School of Public Health, Social and Behavioural Health

Sciences, University of Toronto; Toronto, Canada
} 
Qualitative analysis of English and Welsh trade response to CIPs

02079272786

elizabeth.mcgill@1shtm.ac.uk 


\title{
Challenging, co-operating and splitting: a qualitative analysis of how the trade press responded to Cumulative Impact Policies in England and Wales
}

\begin{abstract}
Introduction: Cumulative impact policies (CIPs) increase English and Welsh local authority powers to regulate licences to sell alcohol. Commercial actors' responses to CIPs potentially affect implementation and impacts. An analysis of the trade press provides perspectives on how commercial actors respond to this intervention.
\end{abstract}

Method: Qualitative, thematic analysis of trade press articles (published 2003-2016, n=6 trade journals) focusing on depictions and responses to CIPs, including strategies for commercial actors engaging with the intervention.

Results: Included articles $(\mathrm{n}=259)$ provided both positive, but more typically, negative depictions of CIPs. CIPs were criticised for being unfair and an economic threat. Legal challenges to CIPs were at times advocated. Partnership and dialogue with local authority stakeholders were presented as a means by which licence applicants could promote their commercial interests in areas where CIPs were implemented, or as an alternative to regulatory interventions such as CIPs. Some alcohol retailers hoped CIPs could protect their businesses from market competition.

Conclusions: Commercial actors do not respond uniformly to alcohol regulation. This study of CIPs found that at times different commercial interests could be served by directly challenging the intervention or strategically co-operating with implementers. Implementation and evaluation of such interventions should consider commercial actors' responses.

Key words: alcohol policy, cumulative impact policy, public health, trade press analysis 


\section{Challenging, co-operating and splitting: a qualitative analysis of how the trade press responded to Cumulative Impact Policies in England and Wales}

\section{Introduction}

Alcohol is a major contributor to the global burden of disease and injury (World Health Organisation, 2014). It is also an issue where public health goals can come into conflict with those of the commercial sector (Adams, Buetow, \& Rossen, 2010; Babor, 2009; Casswell, 2009; Kickbusch, 2012; McCambridge, Hawkins, \& Holden, 2013; Moodie et al., 2013; West \& Marteau, 2013). Attempts to find common ground that can reconcile public health concerns with commercial interests have been advocated but also criticised (Freudenberg, 2014; McCambridge, 2012; Miller, de Groot, McKenzie, \& Droste, 2011; Petticrew, Lee, \& McKee, 2012). A key point of dispute relates to whether the commercial imperative to maximise profits through alcohol sales can be reconciled with public health aims to prevent and reduce harm through reduced alcohol consumption (Adams et al., 2010; Babor, 2009; Babor et al., 2010; Casswell, 2013; Science and Technology Select Committee, 2011). Industry's potential conflict of interest around alcohol harm reduction has become a research focus. It has led some researchers to examine how commercial actors attempt to influence public health policies through linguistic techniques and arguments used to frame political discourses around alcohol and health, and by direct lobbying activities and involvement in policy decision-making processes (Anderson, Chisholm, \& Fuhr, 2009; Greenaway, 2011; Hawkins \& Holden, 2013; Holden \& Hawkins, 2013; Szmigin et al., 2008).

Proposals for increased regulation and restriction of alcohol availability is a particularly contentious issue. Such approaches have been opposed by sections of the alcohol industry in favour of voluntary and industry-led approaches (Martino, Miller, Coomber, Hancock \& Kypri, 2017; McCambridge, Hawkins \& Holden, 2013; Savell, Fooks \& Gilmore 2016). For 
example, in the United Kingdom (UK), numerous studies have explored how different alcohol industry actors framed their opposition to (so far unimplemented) proposals for legislation to set a minimum price on beverages based on alcohol content (minimum unit pricing, or MUP) (Hawkins, Holden \& McCambridge, 2012; Hawkins and Holden, 2013; Holden, Hawkins \& McCambridge, 2013; Katikireddi et al., 2014; Katikireddi \& Hilton 2015).

Industry-led and public private partnership approaches to alcohol harm reduction have been advocated as an alternative to regulation, but have also drawn criticism from some researchers (Brownell \& Warner, 2009) and other commentators (Science and Technology Select Committee, 2011). A recent evaluation of the English Responsibility Deal, an intervention where commercial actors made voluntary commitments to reduce harms, found that industry commitments where much more likely to focus on promoting behavioural change amongst drinkers, rather than on regulating alcohol availability (Knai, Petticrew, Durand, Eastmure, \& Mays, 2015; Knai, Petticrew, Mays, Durand, \& Eastmure, 2015). In contrast, a review of systematic reviews of alcohol interventions identified a pattern of international research evidence to support the use of regulatory or statutory enforcement interventions, including those that restricted alcohol availability, over behavioural and voluntary approaches (Martineau, Tyner, Lorenc, Petticrew, \& Lock, 2013).

\section{Local interventions}

Much of the research on the commercial sector's response to alcohol regulation has focused on national or state-wide interventions, but in the UK (and elsewhere), local authorities have powers to implement and shape their own regulatory interventions (Maclennan, Kypri, Room \& Langley, 2012; Martineau, Graff, Mitchell \& Lock, 2013). Local government is therefore a key setting where public and private sectors intersect. The question of how the commercial 
sector responds to regulatory interventions at the local level has received little attention from researchers, even though implementers can potentially benefit from understanding why and how commercial actors can oppose, work with or seek to influence specific interventions (Egan et al, 2016).

We examined the response of commercial actors to a particular intervention in England and Wales that enhances local authority powers to regulate alcohol availability. To do this, we have reviewed and thematically analysed coverage relating to the intervention in the trade press (journals written for commercial sector audiences including those involved with the alcohol trade). We took a qualitative approach to provide a nuanced understanding of the kinds of arguments and response strategies that have been presented to the commercial readership of those journals. The intervention we focus on is the Cumulative Impact Policy.

\section{Intervention and policy context}

The intervention of interest in this paper - the Cumulative Impact Policy (CIP) - was initially described in Guidance Issued Under Section 182 of The Licensing Act 2003 (the Guidance) (Woodhouse, 2015). CIPs allow licensing authorities, who regulate alcohol sales at a local authority level, the option of designating sub-areas as Cumulative Impact Zones (CIZs), where they can demonstrate that the density of outlets selling alcohol is undermining at least one of four statutory licensing objectives provided by the 2003 Act. These objectives are (i) prevention of crime and disorder; (ii) public safety; (iii) prevention of public nuisance and (iv) protection of children from harm (Home Office, 2017).

CIPs provide licensing authorities with additional legal backing to reject or modify licence applications in (CIZs) (Egan et al., 2016; Grace, Egan, \& Lock, 2016; Martineau, Graff, Mitchell, \& Lock, 2013). Where CIPs are not enforced, the onus is on statutory bodies 
designated as 'responsible authorities ${ }^{3}$ to demonstrate that an application for a new or modified alcohol licence will compromise a licensing objective (Woodhouse, 2015). Within a CIZ, the burden of proof is reversed; licence applicants must demonstrate that their application will not compromise any objective. By March 2016, there were 215 CIPs implemented by just under a third $(n=106)$ of local licensing authorities across England and Wales (Home Office, 2016).

CIPs originally applied to on-licences (where drinks can be consumed on the premise). The policy has expanded over time to also include off-licences (shops or other premises where purchased drinks must be consumed off-site), depending on local considerations (Wilmore, 2010a). New Guidance recognised this in 2012 (Home Office, 2012).

CIPs have been implemented within the context of broader policy developments affecting alcohol licensing since the 2003 Act. The Police Social Reform and Social Responsibility Act (2011) made local health authorities 'responsible authorities,' thus enabling them to make representations against licence applications. The same Act gave local authorities new policy options that can be implemented independently of CIPs, including Early Morning Restriction Orders (EMROs) and Late Night Levies (LNLs). An EMRO can restrict the sale of alcohol between midnight and 6 am, whereas the LNL levies an additional fee on alcohol retailers who trade after midnight (Martineau, Graff, Mitchell \& Lock, 2013).

The Government's Alcohol Strategy (2012) proposed adding a licensing objective that would aim to protect and promote public health, although this has not been enacted in England or Wales (Martineau, Graff, Mitchell, \& Lock, 2013). In contrast, Scotland has a 'health licensing objective' (Fitzgerald, 2015; Nicholls, 2015; Woodhouse, 2015). However, some of

\footnotetext{
${ }^{1}$ The responsible authorities include the licensing authority and the leads from the police, fire and rescue, health and safety, environmental health, planning, child protection, trading standards, immigration enforcement and public health. (Martineau, Graff, Mitchell \& Lock, 2013).
} 
the policy options available to licensing authorities in England and Wales are not available in Scotland, or take a different form and are administered through different local government structures. Instead of CIPs, Scottish authorities are required to include within their Statement of Licensing Policy a statement on 'overprovision' of alcohol (Fitzgerald, 2015; Nicholls, 2015; Woodhouse, 2015). Because of the contextual differences between Scotland, and England and Wales, this paper focuses on CIPs in England and Wales.

\section{Methods}

We conducted a qualitative thematic analysis of articles we identified from the trade press that discussed CIPs in England and Wales, to explore how commercial actors perceived and responded to this intervention.

\section{Document search}

A search of the trade press was conducted by first identifying relevant sources using Google and Nexis UK searches. The two most prominent sources were the Morning Advertiser (MA) and the $M \& C$ Report $(M \& C)$; additional sources analysed included OffLicence News, Forecourt Trader, Convenience Store and The Grocer.

The timeframe of January 1, 2000 to November 20, 2016 was selected to include discussion of cumulative impact regulation in the lead up to the 2003 Licensing Act and also to include a subsequent time period when the Act, the Guidance and early adopters of CIPs were likely to receive trade press coverage. The initial searches were conducted in the summer of 2014 and relevant articles were identified through the $M A$, the $M \& C$ and Forecourt Trader and The Grocer websites' search functions using the search term "cumulative impact." Additional searches using Nexis UK identified relevant articles from the print magazine editions of the $M A$ and the $M \& C$, and articles from OffLicence News, and Convenience Store. The search 
was subsequently updated in December 2016 utilising the search function on each journal's website.

The $M A$ and $M \& C$ write for different facets of the pub and restaurant sector; the $M A$ 's primary audience is publicans, and they aim to 'advise, campaign and speak for the license pub operator' (WilliamReed Business Media 1). The $M \& C$ also speaks to this sector and describes its audience as 'senior managers, investors and analysts in the restaurant and pub markets' (WilliamReed Business Media 2). OffLicence News and Convenience Store write for the off-licence and neighbourhood-retailing sector (WilliamReed Business Media 3 and 4); whereas the Forecourt Trader and The Grocer aim to reach the petrol-retailers (including supermarkets) and all facets of the fast-moving consumer goods (FMCG) sector, respectively (WilliamReed Business Media 5 and 6). All the included journals are owned by WilliamReed Business Media Ltd.

\section{Analysis}

Each article was read to determine whether it fit the inclusion criterion: the term 'cumulative impact' had to refer to alcohol licensing policy. The research team classified included studies as 'news articles,' 'editorials/opinions,' 'features,' and 'advice pieces' based on the section on which they appeared in their respective publication, and the researchers' understanding of the aim of the article. Information on the author's affiliation and sources cited was also extracted. The initial coding framework was developed from a sample of 20 articles. Codes were developed to extract data on the type and authorship of articles; places referred to in articles; types of premise or commercial actor referred to; arguments in support of or opposition to CIPs; strategies advanced for working with or challenging CIPs; economic, social, health or legal issues referred to in discussions of CIPs. Following coding, categories of codes were aggregated into broader themes based on discussions between researchers $(\mathrm{DH}$, 
DG, ME). As a secondary analysis of published data, this study did not require an ethics committee submission.

Some descriptive statistics about the dataset are provided along with a narrative description of how article content reflected policy developments over time. However, we have not conducted a content analysis that seeks to quantify the content of trade press texts over time, or by type of writer or journal. Instead, we utilised a qualitative thematic analysis in order to allow for a richer, and more nuanced understanding of how different actors in this process respond to the policy in question through a particular medium -trade journals. As the included studies were heavily skewed towards the $M A$, we did not compare content between journals.

\section{Results}

\section{Description of the dataset}

Of 323 articles identified in the search, 259 met the inclusion criteria for coding and analysis. 196 articles were published in the $M A, 52$ in the $M \& C, 6$ in OffLicence News, 2 in Forecourt Trader, 1 in Convenience Store and 0 in The Grocer. The 259 articles included news items, editorials and opinion pieces, advice for licensees and features. In line with its stated aim and audience, the $M A$ included a significant number of advice and opinion items for licence holders, many of which were written by legal experts. In contrast, the sample from the $M \& C$ contained mostly news articles, alongside a few feature pieces. Around half of the articles were anonymous and most of the remainder were attributed to journalists. Approximately one in ten were written by legal experts, industry representatives or other professionals involved in licensing. 
Articles in the sample drew on a range of sources in their reporting, including trade organisations representing different parts of the alcohol industry, individual licensees and local government representatives. The most prominent sources were legal and trade experts, who were quoted frequently and extensively across all the types of articles. Solicitors from Poppleston Allen, a firm specialising in licensing, were particularly prominent but other legal experts also featured. Their role included authoring legal advice and opinion articles in the $M A$. They were also cited frequently in news articles, for example providing opinions on specific legal cases. Representatives from trade organisations such as the British Beer and Pub Association (BBPA) and the Association of Multiple Licenced Retailers (AMLR) also featured. The BBPA often provided perspective on national policy changes and specific legal challenges, while the AMLR provided critiques of council policy and their application of CIPs, as well as a narrative about the economic benefits of pubs. In contrast with quotes from legal and trade experts, quotes from local councillors or local government representatives tended to be less discursive and limited to brief factual points about CIP changes.

The number of articles about CIPs, and their content, varied over the sample timeframe, reflecting developments in the policy process. Before and after the passage of the 2003 Licensing Act, a small number of articles were published describing and providing opinions on CIP proposals. Following the implementation of the Licensing Act in 2005, coverage of CIPs increased to around 17 articles per year. Such articles reflect the policy's early 'bedding in' period, in that they often focused on early adopters, or local area consultations about adoption, as well as articles describing early legal challenges to CIPs and opinions about the merits and potential impact of the policy. Prior to 2010, most discussions of CIPs related to the on-trade (although Westminster City Council's early attempts to consider cumulative impacts of off-licences attracted some attention). After 2010, off-licences began to garner more attention in the trade press as Westminster, and subsequently other local authorities, 
chose to expand their CIPs to include off-licences, as well as on-licences. CIP Guidance issued in 2012 marked a shift in position on off-licenses by removing language regarding the application of CIPs exclusively to on-licences (Home Office, 2010; Home Office, 2012). The Police Social Reform and Responsibility Act (2011) and The Government's Alcohol Strategy (2012) also attracted the attention of the trade press and coincided with a further increase in coverage until 2013. From 2014, the numbers of articles published per year has gradually fallen, and in 2016, the final year included in this sample, a total of 17 articles were published on CIPs across the sample.

\section{Themes}

We mapped out three overarching themes across journals: 1) negative depictions of CIPs; 2) support for CIPs; and 3) advice on responding to CIPs. We describe these themes, and report on sub-themes, in the sections below.

\section{1) Negative depictions of CIPS}

Some articles challenged CIPs by describing the policy in ways that were explicitly or implicitly critical; we analysed 180 articles with critical content, although criticisms varied in directness and could sometimes feature alongside more positive view points. Negative framings of CIPs typically invoked questions of fairness or economic impact.

\section{CIPs as unfair}

Organisations and individuals who represent licensed premises, or support applications for new or varied premises, depicted CIPs as unfair by drawing on a range of arguments including concern that the policy was too comprehensive, that it would lead to specific licence applications no longer being judged on their individual merits and/or that it was too punitive. For example, the spokesman for a licensee association referred to CIPs as 'blanket rebuttal policies' (news article) (M\&C Report Team, 2011) and a 'blunt instrument' (news 
article) (M\&C Report Team, 2011). An unnamed author writing in the 'Legal' section of the $M A$ characterised CIPs as a form of 'draconian legislation' (advice piece) ("Licensees run the risk of over-zealous enforcement," 2013).

Many articles argued that the underlying assumptions of a CIP are unfair because they are targeted at new applicants rather than current licence holders who operate their businesses irresponsibly. Representatives from Poppleston Allen argued that a CIP 'maintains the status quo' (editorial) (Poppleston Allen, 2016). Other articles published in both the early and later periods of the study went further, calling CIPs 'a safety net for those poor operators who would otherwise be forced out of business by new competition' (news article) ("Brighton's zone will stifle pubs," 2007). Echoing this statement, a news article published eight years later included a quote from a Poppleston Allen solicitor, arguing:

There is always a danger in imposing a CIP of throwing the baby out with the bathwater, in that responsible operators who wish to extend their hours or open new premises in such an area are prevented from doing so whilst less responsible operators can continue to trade simply because they were there first (news article) (Sutherland, 2015).

Others argued that a focus on the number of licensed premises, as opposed to their quality, is a misguided use of local authorities' powers; in an article published in Forecourt Trader, for instance, the Chief Executive of the Association of Convenience Shops was quoted as saying:

We continue to oppose the use of CIPs to reduce alcohol related harm. Limiting the number of licensed premises in an area only deters new stores from opening instead of dealing with the existing problems. Local authorities should focus on the quality and compliance levels of the retailers in the market (news article) (Wood, 2016).

\section{CIPs as uneconomical}

CIPs were also portrayed as an economic threat to local economies by hindering local-level investment. For example, an article in the $M A$ with no attributed author argued: 'The 
detrimental effect of cumulative impact policies is that they can stifle innovation, new concepts and prevent proper development of the late-night economy' (advice piece) ("BrewDog's licensing victory," 2012). A representative from Poppleston Allen stated that CIPs 'are leading to growing numbers of closed and unlettable buildings, fewer numbers of pub and bar openings, and lack of investment due to lack of competition' (news article) (Bothwell, 2015b).

The costs of legally appealing licence decisions in CIP areas were presented as a burden to both applicants and local authorities. For example, following a successful appeal for a nightclub licence within a CIZ, the solicitor representing the licensee argued: 'The time and money wasted in this matter is huge and the fact the council agreed to pay $£ 2,500$ towards $\mathrm{Mr}$ Weeks' costs speaks volumes in that they knew the original decision was wrong' (news article) (Bothwell, 2015a).

\section{2) Support for CIPs}

We identified 36 articles that included positive perspectives on CIPs. Some of the more positive comments came from professionals involved in local licensing systems, who were occasionally quoted in articles.

\section{CIPs as preferable to other interventions}

Following the implementation of the Police Social Reform and Responsibility Act (2011), a number of articles argued that CIPs were preferable to the regulatory interventions associated with that legislation. For example, a Norwich police licensing officer argued that CIPs " "have been championed by the trade" as an alternative measure to early morning restriction orders' (news article) (Bothwell, 2015c). In another article, an unnamed author described a local authority contemplating the powers available to them to address alcohol-related disorder. The 
author made the case that CIPs, LNLs and EMROs are all unfair on the trade, but that a CIP might be the least damaging:

As for those councils, such as Brentwood in Essex, that are having public meetings in the near future to consider all three options LNL, EMRO and CIP I hope they will think very carefully before committing to any proposal that further burdens the night-time economy. If they do choose one, however, then perhaps a CIP is the fairest of the three it at least maintains the status quo, and allows existing operators to address any problems on a voluntary basis (advice piece) ("Handling the late-night trade," 2013).

\section{Using CIPs to address market competition}

Other articles suggested support for a CIP may emerge from a fragmented alcohol market with competing interests. Existing licence holders could welcome CIP restrictions on new premises opening in local markets already perceived to be overly competitive. For example, one article reported that 'earlier this week licensees in Swansea told the Publican's Morning Advertiser that they welcomed the proposed measures and agreed that 250 licensed premises in the city was enough' (news article) (Bothwell, 2013a). The Bar Entertainment \& Dance Association (BEDA) was one of two trade organisations to welcome the CIP in Blackpool; the chairman of the organisation explained 'in my small town of Scunthorpe (Lincolnshire), instead of having one new licence every five years, which was probably sustainable, you get five new licences every year. And, of course, we end up with far too many licences for too few people' (feature) (Bothwell, 2013b).

The on- and off-trades could also be depicted as rival interest groups, notably, in articles where on-trade representatives supported the use of CIPs to restrict off-licences. For example, a licensee of a pub in Watford argued in favour of focusing CIPs on off-licences: '[it's] a very good idea. There are so many off-licences. Then it's the same old scenario, where they are drunk before they come to the town centre, then pubs get the backlash' (news article) (Wilmore, 2010b). In an article describing Westminster's early use of CIPs in relation to the 
off-trade ('Westminster plans radical off-trade clampdown,'), the Westminster Licensees Association supported the local authority's plans; their secretary argued:

This is the first time I've seen a licensing authority raise the point that they don't have enough control of the off-trade, so we are fully behind them on this. [...] We would be willing to support a joint lobbying approach from Westminster Council and the trade to give local authorities greater powers and discretion to regulate off-sales and hence minimise the adverse public order effects. (news article) (Wilmore, 2010a).

\section{3) Advice on responding to CIPS}

\section{Legal challenges to CIPs and the licensing regime}

A large number $(n=141)$ of articles either cited or were written by legal experts and we identified 53 articles that described direct action, often through the courts, in order to challenge CIPs. Following the enactment of the Licensing Act in 2005, legal action was at times advocated as a means of clarifying both local and national policy and regulation. A lawsuit brought by three trade organizations was described as 'part of a larger strategy that sought to clarify the powers of local authorities under the new Act' (news article) ("A Canterbury Tale," 2005). Cases that were brought to the courts shortly after the implementation of a new CIP were seen as a valuable means of understanding the policy in a particular area was being enforced.

Legal challenges were also framed as courageous. For example, an applicant who appealed the rejection of his extension of hours application was called 'brave' (news article) (Harrington, 2008) and advice was given that 'these applications are often not for the faint hearted and we have also had to deal with appeals against the decisions of licensing sub committees' (editorial) (Poppleston Allen, 2016).

Along with general encouragement, some articles attempted to provide more specific advice about legally challenging new licensing policies. Readers of the $M A$ were advised in an 
article with no attributed author that they could appeal decisions where they felt the local authority acted in a way that ran counter to the Guidance on CIPs:

A careful reading of the condition which the Guidance sets reveals that there are many points in the exercise where local authorities could face challenge if they do not get it right. And of course aggrieved applicants can take them to appeal if they stray from the recommended path (editorial) ("Saturation policies for councils have pitfalls," 2004).

Specific cases were discussed in the trade press illustrating that victory in appeals was possible for licensees. These cases were portrayed as small reasons for optimism within the context of a challenging licensing regime. One such example cited in several articles was a case in Leeds where a licence was awarded on an appeal to open a BrewDog establishment serving craft beers; one article describing the decision quoted a Poppleston Allen licensing solicitor arguing the decision represented 'a rare victory for operators and the burden they face being within stress/cumulative impact areas and suggests there is some light at the end of the tunnel for good operators looking to start a business in areas within a council's CIP' (news article) (M\&C Report Team, 2012).

\section{Strategic co-operation and partnership}

Not all the advice given to readers emphasised direct legal challenge and, as stated earlier, the high cost and risks of such challenges were at times acknowledged. As time passed following the enactment of the Licensing Act and as more and more areas adopted a CIP, alcohol retailers were encouraged to take action that would improve their chances of securing desired outcomes in areas that had CIPs: for example, by becoming familiar with the local policies, processes and the relevant stakeholders. An article written in the $M A$ that gave advice to publicans described what is required in order to have a chance at getting an application approved: 
[...] a great deal of preparation work needs to go into a licence application even before the application process itself begins. Operators need to know what sort of opposition they are going to face, and be prepared to compromise on some aspects of the operation if they come up against fierce residential or environmental health objections (advice piece) (Coulson, 2012).

Another advice piece emphasised the need for prior engagement with a range of relevant stakeholders including responsible authorities (particularly the police) and neighbouring premises. Even though the article refers to the BrewDog legal challenge in Leeds, the emphasis on listening and engaging in the quote below strikes a seemingly more co-operative tone compared to some of the other articles:

When making an application, always try and engage with the police, the responsible authorities and your neighbours before you submit the application. Meet with them, describe your proposals and listen to what they have to say. The earlier you can engage them the better (advice piece) ("BrewDog's licensing victory," 2012).

Various forms of local stakeholder engagement and 'partnership' were advocated in articles, sometimes as a preferable alternative to court action. Commentators with legal backgrounds sometimes advanced this view. For instance, the chairman of Best Bar None, and a solicitor, spoke about the growth in local partnerships and communication between applicants and the responsible authorities in a positive light, arguing:

I think it has been crucial over the past few years that we walk away from the very adversarial atmosphere of the courtroom setting where licensing business was conducted, so that there is a much greater sense of dialogue and partnership between regulators and the UK's publicans (feature) ("Beacon of best practice," 2012).

Partnerships were also framed as a preferred alternative to top down legislative approaches to alcohol regulation such as CIPs. For example, some members of the alcohol trade advocated communication and partnerships as opposed to regulation from governments; here the chief executive of the Campaign for Real Ale argues: 
In our opinion, it would be better if the relationship were a partnership between the licensing authority, the licensee and the police. We've noticed that a number of local authorities are turning away from latenight levies and other cumulative impact policy type setups to voluntary partnership arrangements, such as business improvement districts. We think this is a very good development and one that should be reflected in the Licensing Act, if it's amended (news article) (Coleman, 2016).

\section{Discussion}

We have conducted a documentary analysis of trade press coverage of Cumulative Impact Policies. The analysis examined how commercial actors responded to an intervention that enhanced local government powers to regulate the alcohol trade through the licensing system. The responses we identified were diverse and included both oppositional and supportive statements.

We suggest two points that are important to consider when interpreting these findings. First, whilst we introduced this paper by framing alcohol regulation as a health issue, the trade articles we identified tended not to engage with health. Unsurprisingly, they more typically discussed CIPs and regulation in relation to the commercial and economic interests relevant to the readership. Nonetheless, it is widely accepted that alcohol availability affects health (Babor et al, 2010), and so the ways in which the commercial sector choose to either oppose or work with policies affecting alcohol availability are highly relevant to a public health audience.

Second, our qualitative approach to examining the trade press has allowed us to gain a more nuanced understanding of trade responses to CIPs. We find that it is not sufficient to say that some commercial actors support CIP and some oppose it. Rather, both support and opposition can be seen as strategies employed to advance commercial interests. Different strategies may serve the interests of a particular actor at different times, or (as we have found in this study) 
there may be occasions when different responses reveal competing interests and splits within the commercial sector.

In this study, we identified three broad types of response to CIPs, which we refer to here as 'challenging', 'strategic co-operation' and 'splitting'.

'Challenging' includes direct criticism of the policy by commentators who, for example, depict the intervention as unfair, economically damaging, adversarial and unworkable. It also includes encouraging licence applicants to take direct action including legal action, although some contributors (including legal professionals) warn that the legal route is a potentially expensive risk.

'Strategic co-operating' refers to attempts by commercial actors to work with policy structures and networks including those relevant to CIPs in ways that advance their interests. Applicants are advised to increase their chances of making successful licence applications without risky recourse to legal action by gaining familiarity with local authority policies and processes, engaging in dialogue with key stakeholders and being prepared to adapt their application. At other times, co-operation at a local policy level is advocated as a means of giving private sector stakeholders a say in local licensing policies: this kind of public-private partnership approach to local policy is sometimes portrayed as a preferred alternative to, and a potential means of avoiding, regulatory approaches such as CIPs.

Finally, 'splitting' echoes what Holden et al. have referred to as 'cleavages' within a segmented alcohol industry (Holden, Hawkins, \& McCambridge, 2012). Trade press articles at times reveal the perspectives of commercial actors who support CIPs on the grounds that the intervention might tackle what some perceive to be a greater threat of competition from other sections of the alcohol trade. Our analysis identifies different types of split: notably 
existing licence holders hoping CIPs can prevent new premises from opening; and on-licence retailers hoping to shift the focus of CIPs from pubs to off-licences.

\section{Research implications}

The current study is novel in its focus on local alcohol policy, and specifically CIPs, where the commercial response is not solely at the corporate level but also involves the activities of individual licence applicants. Hence, the kinds of response we identify are multi-levelled: some were targeted at influencing broader policy, whilst others were concerned with helping specific retailers through the licensing process. Much of the previous literature has focused on national policy, but we have identified clear parallels with our own findings. For example, considering recent work on MUP, we find examples of commercial actors opposing the policy by arguing that the sector provides a positive economic contribution to society that risks being undermined (Holden \& Hawkins, 2013). There are also examples of disunity within the commercial sector including some stakeholders within the on-trade arguing that MUP appropriately targeted the off-trade where inexpensive beverages are sold (Hawkins, Holden \& McCambridge, 2012; Hawkins \& Holden, 2013; Katikireddi \& Hilton, 2015).

Previous literature has also highlighted potential problems associated with partnership approaches to alcohol policy (Adams et al., 2010; Baggott, 2006; Knai, Petticrew, Durand, Eastmure \& Mays, 2015; Giesbrecht, Johnson, Anglin, Greenfield \& Kavanagh, 2004). Studies have also been conducted for other sectors such as food and tobacco and found evidence of comparable responses (Bond, 2010; Jensen \& Ronit, 2015; Kickbusch, 2012; Marks, 2014; Moodie et al., 2013; Orford, 2013; Petticrew, Lee \& McKee,2012; Ronit \& Jensen, 2014). However, the similarities of approach across commercial sectors should not be overstated: a recent Australian study found similarities but also differences between alcohol and tobacco industry lobbying, with the alcohol industry placing a heavier emphasis (contrary 
to the current evidence base) on notions of regulatory redundancy and insufficient evidence (Martino, Miller, Coomber, Hancock \& Kypri, 2017).

This study adds to this evidence by considering local-level alcohol interventions and has employed a unique approach by using the trade press as its data source. Evaluations of complex interventions affecting public health have frequently neglected the role of commercial actors. Yet, commercial responses to interventions such as those affecting alcohol availability may potentially impact on implementation processes and outcomes (McGill, Marks, Sumpter, \& Egan, 2016). If, as it has been advocated, interventions are considered as events in complex systems, then researchers face the challenge of finding ways to assess activities and responses that occur across the system (Hawe, Shiell, \& Riley, 2009; Walton, 2014). We have attempted to do this with respect to commercial actors that comprise part of the 'CIP system' in this study, although we accept that this work requires further methodological development - as part of a more general need to develop our approaches to understanding public health systems.

\section{Limitations}

The findings of this study are dependent on the sampling used and thus may not be fully representative of commercial opinions on the issue of CIPs. Notably our data source provides depictions of CIPs that were produced for open publication rather than more privately held opinions. The search strategy was limited by the availability of data and by the online search engines through which we searched included journals. The search strategy term looked precisely at 'cumulative impact,' and thus may have potentially missed articles that discussed CIPs without using that term, although to our knowledge a 'cumulative impact policy' does not have a large number of synonyms. In addition, our analysis focussed specifically on England and Wales, and therefore, did not include the term 'overprovision' which would 
have identified articles regarding Scotland's attempts to address alcohol market saturation. Finally, although the trade journals varied, those with articles that we identified for our sample were owned by the same media company, William Reed Business Media, and thus may reflect the parent company's views and preferences. Our background research on trade press, however, suggest that the sampled sources dominate the UK market for this type of media.

\section{Conclusion}

Based on the articles in our sample, the trade press presents a diverse range of opinions and responses to CIPs. However, underlying this diversity we find a pattern of responses that has parallels with those that previous studies have identified for other policies affecting the availability of alcohol or other health-related consumables.

Any restriction of alcohol availability takes place within a complex system. The aims, implementation and impacts of such interventions may vary from area to area and prompt a range of responses from commercial actors who seek to influence the adoption, implementation and impacts of the intervention. At times, these responses reveal competing interests within the commercial sector. Local, as well as national, decision-makers and implementers should be aware that commercial responses to policy are designed to further commercial interests even when partnership, rather than adversarial, approaches are adopted. This raising of awareness is particularly important to public health practitioners given the potential for commercial interests to conflict with the goals of improving health and reducing health inequalities at the population level. 


\section{Acknowledgements}

The authors thank Professor Mark Petticrew and Dr Niamh Fitzgerald for their helpful comments on a draft of this paper.

\section{Funding}

This research is funded by the NIHR School for Public Health Research (SPHR). The views expressed are those of the author(s) and not necessarily those of the NHS, the NIHR or the Department of Health. SPHR is a partnership between the Universities of Sheffield, Bristol, Cambridge, Exeter, UCL; The London School for Hygiene \& Tropical Medicine; the LiLaC collaboration between the Universities of Liverpool and Lancaster and Fuse; The Centre for Translational Research in Public Health, a collaboration between Newcastle, Durham, Northumbria, Sunderland and Teesside Universities.

\section{Disclosure of interests}

The authors report no conflicts of interest.

\section{References}

Adams, P. J., Buetow, S., \& Rossen, F. (2010). Vested interests in addiction research and policy poisonous partnerships: health sector buy-in to arrangements with government and addictive consumption industries. Addiction, 105(4), 585-590.

Anderson, P., Chisholm, D., \& Fuhr, D. C. (2009). Effectiveness and cost-effectiveness of policies and programmes to reduce the harm caused by alcohol. The Lancet, 373(9682), 2234-2246.

Babor, T., Caetano, R., Casswell, S., Edwards, G., Giesbrecht, N., \& Graham, K. (2010). Alcohol: no ordinary commodity. Research and public policy (2nd ed.). Oxford: Oxford University Press.

Babor, T. F. (2009). Alcohol research and the alcoholic beverage industry: issues, concerns and conflicts of interest. Addiction, 104(s1), 34-47. 
Baggott, R. (2006). Alcohol strategy and the drinks industry: a partnership for prevention? York: Joseph Rowntree Foundation.

Beacon of best practice. (August 16, 2012). Morning Advertiser.

Bond, L. (2010). Selling addictions: similarities in approaches between Big Tobacco and Big Booze. Australasian Medical Journal, 3(6), 325-332.

Bothwell, E. (August 2, 2013a). Swansea Council approves cumulative impact policy. Morning Advertiser.

Bothwell, E. (September 26, 2013b). Liberalisation or the route to restriction?. Morning Advertiser.

Bothwell, E. (February 4, 2015a). Nightclub in cumulative impact zone granted 6am licence. Morning Advertiser.

Bothwell, E. (February 13, 2015b). MA300: Health lobbyists 'increasingly influential' in licensing decisions. Morning Advertiser.

Bothwell, E. (February 25, 2015c). Industry figures fear cumulative impact policy plans. Morning Advertiser.

BrewDog's licensing victory. (October 4, 2012). Morning Advertiser.

Brighton's zone will stifle pubs. (October 25, 2007). The Publican's Morning Advertiser.

Brownell, K. D., \& Warner, K. E. (2009). The perils of ignoring history: Big Tobacco played dirty and millions died. How similar is Big Food? Milbank Quarterly, 87(1), 259-294.

A Canterbury Tale. (August 11, 2005). The Publican's Morning Advertiser.

Casswell, S. (2009). Alcohol industry and alcohol policy-the challenge ahead. Addiction, 104(s1), 3-5.

Casswell, S. (2013). Vested interests in addiction research and policy. Why do we not see the corporate interests of the alcohol industry as clearly as we see those of the tobacco industry? Addiction, 108(4), 680-685.

Coleman, L. (October 20, 2016). CAMRA calls for end of late-night levies. Morning Advertiser.

Coulson, P. (25 January, 2012). Protecting the pubs' interests. Morning Advertiser.

Egan, M., Brennan, A., Buykx, P., De Vocht, F., Gavens, L., Grace, D., . . Mooney, J. D. (2016). Local policies to tackle a national problem: Comparative qualitative case studies of an English local authority alcohol availability intervention. Health \& Place, 41, 11-18. 
Freudenberg, N. (2014). Lethal but legal: corporations, consumption and protecting public health. New York: Oxford University Press.

Fitzgerald, N. (2015). Influencing the implementation of a public health objective in Scottish alcohol licensing: a qualitative interview study - summary report. Stirling, Scotland: Institute for Social Marketing, UK Centre for Tobacco and Alcohol Studies, School of Health Sciences, University of Stirling.

Giesbrecht, N., Johnson, S., Anglin, L., Greenfield, T.K., Kavanagh, L. (2004). Alcohol advertising policies in the United States: National promotion and control initiatives. Contemporary Drug Problems, 31, 673-710.

Grace, D., Egan, M., \& Lock, K. (2016). Examining local processes when applying a cumulative impact policy to address harms of alcohol outlet density. Health \& Place, 40, 76-82.

Greenaway, J. (2011). How policy framing is as important as the policy content: The story of the English and Welsh Licensing Act 2003. British Politics, 6(4), 408-429.

Handling the late-night trade. (April 25, 2013). Morning Advertiser.

Harrington, J. (January 2, 2008). Defeat for Westminster's pub stress zone. The Publican's Morning Advertiser.

Hawe, P., Shiell, A., \& Riley, T. (2009). Theorising interventions as events in systems. American Journal of Community Psychology, 43(3-4), 267-276.

Hawkins, B., \& Holden, C. (2013). Framing the alcohol policy debate: industry actors and the regulation of the UK beverage alcohol market. Critical Policy Studies, 7(1), 53-71.

Hawkins, B., Holden, C., \& McCambridge, J. (2012). Alcohol industry influence on UK alcohol policy: a new research agenda for public health. Critical Public Health, 22(3), 297-305.

Holden, C., \& Hawkins, B. (2013). 'Whisky gloss': the alcohol industry, devolution and policy communities in Scotland. Public Policy and Administration, 28(3), 253-273.

Holden, C., Hawkins, B., \& McCambridge, J. (2012). Cleavages and co-operation in the UK alcohol industry: a qualitative study. BMC Public Health, 12(1), 483.

Home Office. (2010, October). Revised Guidance Issued under Section 182 of the Licensing Act 2003. Retrieved from https://www.gov.uk/government/uploads/system/uploads/attachment_data/file/228955 19781849873499.pdf.

Home Office. (2012, April). Revised Guidance Issued under Section 182 of the Licensing Act 2003. Retrieved from

https://www.gov.uk/government/uploads/system/uploads/attachment_data/file/228877 19780108511400.pdf. 
Home Office. (2016, November). National Statistics: Alcohol and late night refreshment licensing England and Wales 31 March 2016. Retrieved from

https://www.gov.uk/government/publications/alcohol-and-late-night-refreshmentlicensing-england-and-wales-31-march-2016/alcohol-and-late-night-refreshmentlicensing-england-and-wales-31-march-2016\#premises-licences.

Home Office. (2017, April). Revised Guidance Issued under Section 182 of the Licensing Act 2003. Retrieved from

https://www.gov.uk/government/uploads/system/uploads/attachment_data/file/607237 /182Guidance_05_04_17.pdf.

Jensen, J. D., \& Ronit, K. (2015). The EU pledge for responsible marketing of food and beverages to children: implementation in food companies. European Journal of Clinical Nutrition, 69(8), 896-901.

Katikireddi, S.V., Hilton, S., Bonell, C., \& Bond, L. (2014). Understanding the development of minimum unit pricing of alcohol in Scotland: a qualitative study of the policy process. PLoS One, 9(3), e91185.

Katikireddi, S.V., \& Hilton, S. (2015). How did policy actors use mass media to influence the Scottish alcohol minimum unit pricing debate? Comparative analysis of newspapers, evidence submissions and interviews. Drugs: Education, Prevention and Policy, 22(2), 124-134.

Kickbusch, I. (2012). Addressing the interface of the political and commercial determinants of health. Health Promotion International, 27(4), 427-428.

Knai, C., Petticrew, M., Durand, M. A., Eastmure, E., \& Mays, N. (2015). Are the Public Health Responsibility Deal alcohol pledges likely to improve public health? An evidence synthesis. Addiction. 110(8), 1232-1246.

Knai, C., Petticrew, M., Mays, N., Durand, M. A., \& Eastmure, E. (2015). Knai and colleagues' response to comments of the Portman Group in news story about their research on the "responsibility deal" on alcohol. BMJ, 350, h2063.

Licensees run the risk of over-zealous enforcement. (April 18, 2013). Morning Advertiser

M\&C Report Team. (January 11, 2013). Achieving the tipping point. M\&C Report.

M\&C Report Team. (July 6, 2011). Brigton operators slate licence restriction plan. $M \& C$ Report.

M\&C Report Team. (September 17, 2012). Judge slates council for denying BrewDog licence. $M \& C$ Report.

Marks, J. H. (2014). Toward a Systemic Ethics of Public-Private Partnerships Related to Food and Health. Kennedy Institute of Ethics Journal, 24(3), 267-299. 
Maclennan, B., Kypri, K., Room, R., \& Langley, J. (2013). Local government alcohol policy development: case studies in three New Zealand communities. Addiction, 108(5), 885-895.

Martineau, F., Graff, H., Mitchell, C., \& Lock, K. (2013). Responsibility without legal authority? Tackling alcohol-related health harms through licensing and planning policy in local government. Journal of Public Health, 36(3), 435-442.

Martineau, F., Tyner, E., Lorenc, T., Petticrew, M., \& Lock, K. (2013). Population-level interventions to reduce alcohol-related harm: an overview of systematic reviews. Preventive Medicine, 57(4), 278-296.

Martino, F.P., Miller, P.G., Coomber, K.C., Hancock, L., \& Kypri, K. (2017). Analysis of alcohol industry submissions against marketing regulation. PLoS One, 12(1), e0170366.

McCambridge, J. (2012). Dealing responsibly with the alcohol industry in London. Alcohol and Alcoholism, 47(6), 635-637.

McCambridge, J., Hawkins, B., \& Holden, C. (2013). Industry use of evidence to influence alcohol policy: a case study of submissions to the 2008 Scottish government consultation. PLoS Med, 10(4), e1001431.

McGill, E., Marks, D., Sumpter, C., \& Egan, M. (2016). Consequences of removing cheap, super-strength beer and cider: a qualitative study of a UK local alcohol availability intervention. BMJ Open, 6(9), e010759.

Miller, P. G., de Groot, F., McKenzie, S., \& Droste, N. (2011). Vested interests in addiction research and policy. Alcohol industry use of social aspect public relations organizations against preventative health measures. Addiction, 106(9), 1560-1567.

Moodie, R., Stuckler, D., Monteiro, C., Sheron, N., Neal, B., Thamarangsi, T., . . Group, L. N. A. (2013). Profits and pandemics: prevention of harmful effects of tobacco, alcohol, and ultra-processed food and drink industries. The Lancet, 381(9867), 670679.

Nicholls, J. (2015) Public health and alcohol licensing in the UK: challenges, opportunitities, and implications for policy and practice. Contemporary Drug Problems. 42(2), 87105.

Orford, J. (2013). Power, powelessness and addiction. Cambridge: Cambridge University Press.

Petticrew, M. P., Lee, K., \& McKee, M. (2012). Type A behavior pattern and coronary heart disease: Philip Morris's “crown jewel”. American Journal of Public Health, 102(11), 2018-2025.

Poppleston Allen. (March 21, 2016). Cumulative impact policies: the fears over their use. Morning Advertiser 
Ronit, K., \& Jensen, J. D. (2014). Obesity and industry self-regulation of food and beverage marketing: a literature review. European Journal of Clinical Nutrition, 68(7), 753759.

Savell, E. Fooks, G., \& Gilmore, A.B. (2016). How does the alcohol industry attempt to influence marking regulations? A systematic review. Addiction, 11(1), 18-32.

Saturation policies for councils have pitfalls. (April 15, 2004). The Publican's Morning Advertiser.

Science and Technology Select Committee. (2011). Behaviour Change. HL Paper 179 (Second Report, Seession 2010-12). London, UK: The Stationary Office.

Sutherland, E. (September 4, 2015). Licensees say 'no' to all new pubs. Morning Advertiser.

Szmigin, I., Griffin, C., Mistral, W., Bengry-Howell, A., Weale, L., \& Hackley, C. (2008). Re-framing 'binge drinking' as calculated hedonism: empirical evidence from the UK. International Journal of Drug Policy, 19(5), 359-366.

Walton, M. (2014). Applying complexity theory: a review to inform evaluation design. Evaluation and Program planning, 45, 119-126.

West, R., \& Marteau, T. (2013). Commentary on Casswell (2013): The commercial determinants of health. Addiction, 108(4), 686-687.

WilliamReed Business Media 1. Morning Advertiser. Retrieved from http://shop.williamreed.com/store/products, publicans-morning-advertiser_93.htm.

WilliamReed Buisness Media 2. M\&C Report. Retrieved from http://shop.williamreed.com/store/products,mc-report_103.htm.

WilliamReed Buisness Media 3. OffLicence News. Retrieved from http://shop.williamreed.com/store/products, off-licence-news_94.htm.

WilliamReed Buisness Media 4. Convenience Store. Retrieved from http://shop.williamreed.com/store/products, convenience-store_97.htm.

WilliamReed Buisness Media 5. Forecourt Trader. Retrieved from http://shop.williamreed.com/store/products, forecourt-trader_99.htm.

WilliamReed Buisness Media 6. The Grocer. Retrieved from https://www.thegrocer.co.uk/about-us/.

Wilmore, J. (September 9, 2010a). Westminster plans radical off-trade clampdown. The Publican's Morning Advertiser.

Wilmore, J. (September 16, 2010b). Watford to ban new off-licences. The Publican's Morning Advertiser

Wood, J. (April 20, 2016). Warning over alcohol licensing proposals. Forecourt Trader. 
Qualitative analysis of English and Welsh trade response to CIPs

Woodhouse, J. (2015). Alcohol: Cumulative Impact Policies Briefing Paper 07269: House of Commons Library.

World Health Organisation. (2014). Global status report on alcohol and health - 2014. Geneva, Switzerland: World Health Organisation. 